\title{
Studies on the Composition of Egg-White Ovomucin
}

\author{
BY D. S. ROBINSON AND J. B. MONSEY \\ Agricultural Research Council Food Research Institute, Colney Lane, Norwich NOR 70F, U.K.
}

(Received 21 September 1970)

\begin{abstract}
1. Purified ovomucin was isolated as an insoluble glycoprotein complex from thick egg white. 2. A homogeneous glycoprotein, designated $\alpha$-ovomucin, of molecular weight 210000 and containing $N$-acetylglucosamine $(6.7 \%, \mathrm{w} / \mathrm{w})$, $N$-acetylgalactosamine $(0.6 \%, \mathrm{w} / \mathrm{w})$, galactose $(1.8 \%, \mathrm{w} / \mathrm{w})$, mannose $(4.6 \%, \mathrm{w} / \mathrm{w})$, $N$-acetylneuraminic acid $(1.0 \%, \mathrm{w} / \mathrm{w})$ and sulphate $(0.7 \%, \mathrm{w} / \mathrm{w})$, was isolated from preparations of reduced ovomucin by sedimentation equilibrium in a density gradient of caesium chloride formed in the presence of $4 \mathrm{M}$-guanidine hydrochloride. 3. A carbohydrate-rich fraction, designated $\beta$-ovomucin (which is homogeneous by sedimentation-velocity analysis in $5 \mathrm{M}$-guanidine hydrochloride but which is heterogeneous by analytical sedimentation equilibrium in a density gradient of caesium chloride in the presence of $4 \mathrm{M}$-guanidine hydrochloride), containing $N$-acetylglucosamine $(11.0 \%, \mathrm{w} / \mathrm{w}), N$-acetylgalactosamine $(8.7 \%, \mathrm{w} / \mathrm{w})$, galactose $(19.2 \%, \mathrm{w} / \mathrm{w})$, mannose $(4.1 \%, \mathrm{w} / \mathrm{w}), N$-acetylneuraminic acid $(13.8 \%, \mathrm{w} / \mathrm{w})$ and sulphate $(2.7 \%, \mathrm{w} / \mathrm{w})$, was also obtained from preparations of reduced ovomucin by the density-gradient method. 4. Mild acid hydrolysis of the unfractionated ovomucin complex showed that $N$-acetylneuraminic acid occupied a terminal position of the oligosaccharide chains. 5. Alkaline $\beta$-elimination reactions with the unfractionated ovomucin complex indicated that $N$-acetylgalactosamine was linked by alkali-labile bonds to hydroxy amino acids.
\end{abstract}

Ovomucin, first isolated from egg white by Eichholz (1898), is present mainly in the thick white fraction of the domestic hen's egg (Brooks \& Hale, 1961). Although chemical analyses of ovomucin preparations have shown the presence of hexose, hexosamines (Young, 1937; Odin, 1951; Brooks \& Hale, 1961) and cystine (Young, 1937), compared with other egg-white proteins little is known of ovomucin. This is probably because ovomucin is difficult to purify and is completely insoluble after isolation from egg white.

Our previous finding that ovomucin can be dissolved in solutions containing 2-mercaptoethanol and either urea or guanidine hydrochloride (Robinson \& Monsey, 1964) has permitted us to assess the purity of our preparations of ovomucin with physical techniques and has thus helped to make chemical analysis of ovomucin more meaningful. Preliminary reports (Robinson \& Monsey, 1966) have given the chemical composition of our purified preparations of ovomucin and also have described the interactions between reduced ovomucin and lysozyme (Robinson \& Monsey, 1969a,b). Donovan, Davis \& White (1970) have reported the results of physical and chemical studies of unfractionated ovomucin and presented an amino acid analysis for their preparation of ovomucin.
The present paper describes the fractionation of reduced ovomucin by equilibrium sedimentation in a density gradient of caesium chloride formed in the presence of $4 \mathrm{M}$-guanidine hydrochloride. The value of sedimentation-equilibrium densitygradient methods with caesium chloride for the fractionation of glycoproteins has been shown by Creeth \& Denborough (1970).

\section{EXPERIMENTAL}

Materials. Guanidine hydrochloride (British Drug Houses Ltd., Poole, Dorset, U.K.) was recrystallized at pH4.6 as described by Katz (1968). 2-Mercaptoethanol was purchased from Fluka A.-G., Buchs, Switzerland, and redistilled under $\mathrm{N}_{2}$. Iodoacetic acid (British Drug Houses Ltd.) was recrystallized from A.R. ether after the addition of light petroleum (b.p. $80-120^{\circ} \mathrm{C}$. $\mathrm{CsCl}(99.9 \%$ pure) was purchased from Koch-Light Laboratories Ltd., Colnbrook, Bucks., U.K. $N$-Acetylglucosamine, $N$ acetylgalactosamine, glucosamine hydrochloride, galactosamine hydrochloride, $N$-acetylneuraminic acid (type II), $N$-glycollylneuraminic acid (type II) and NOdiacetylneuraminic acid were purchased from Sigma (London) Chemical Co. Ltd., London S.W.6, U.K. $p$-Dimethylaminobenzaldehyde was purchased from Kodak Ltd., Kirkby, Liverpool U.K. Tri-Sil Z was purchased from Phase Separations Ltd., Queensferry, Flintshire, U.K. SE-54 (3\%, w/w) on CQ support (85-100 
mesh) was purchased from JJ's Chromatography Ltd., Hardwick Trading Estate, King's Lynn, Norfolk, U.K. Other reagents were, where possible, A.R. products or laboratory-reagent-grade products. Neuraminidase (type V) from Clostridium perfringens and galactose oxidase were purchased from the Sigma Chemical Co. Glucostat and Galactostat kits were purchased from Worthington Biochemical Corp., Freehold, N.J., U.S.A.

All evaporations were carried out in a rotary film evaporator under reduced pressure at $40^{\circ} \mathrm{C}$.

Preparation of ovomucin complex. The fractions of thick egg white $(400 \mathrm{ml})$ obtained from about 60 eggs newly laid from Thornber 404 hens by using a gauze method (Brooks \& Hale, 1959) were homogenized at the slowest speed in a mechanical blender (MSE Ato-Mix). The crude ovomucin complex was precipitated by the addition of 1 vol. of egg white to 4 vol. of water and purified with $\mathrm{KCl}(2 \%, w / v)$ at $0^{\circ} \mathrm{C}$ as described by Brooks \& Hale (1961). The precipitate was extracted with $\mathrm{KCl}$ until the extract did not contain substances that absorbed light at $276 \mathrm{~nm}$. The purified ovomucin complex was dried with acetone and ether at room temperature.

Hexose analyses. Samples (25 $\mathrm{mg})$ were hydrolysed with $0.5 \mathrm{M}-\mathrm{H}_{2} \mathrm{SO}_{4}(5 \mathrm{ml})$ at $100^{\circ} \mathrm{C}$ in sealed ampoules for various times. The hydrolysates were desalted by passage through a mixed-bed resin (Amberlite MB1). Hexoses were separated by paper chromatography and then eluted with water and determined by the anthrone method (Yemm \& Willis, 1954). Galactose was also determined by the specific galactose oxidase method (Roth, Segal \& Bertoli, 1965). Spectra of the chromogens formed after reaction of the eluted substances with a cysteine- $\mathrm{H}_{2} \mathrm{SO}_{4}$ reagent (Dische, 1955) were compared with those obtained from authentic samples of galactose, glucose and mannose.

Hexosamine analyses. Samples $(10 \mathrm{mg})$ were hydrolysed in $1 \mathrm{ml}$ of $4 \mathrm{M}-\mathrm{HCl}$ at $100^{\circ} \mathrm{C}$ in sealed ampoules for various times. Optimum hydrolysis times were determined as described by Ogston (1964), with internal and external standards of glucosamine and galactosamine at concentrations similar to those found in the experimental samples of ovomucin.

Acid was removed from the hydrolysates by evaporation. Glucosamine and galactosamine in the dried residues were determined by using a Beckman $120 \mathrm{C}$ amino acid analyser. A column $(20 \mathrm{~cm} \times 0.9 \mathrm{~cm})$ of Zeo-Karb 225 resin (particle size $5-8 \mu \mathrm{m}$ ) was eluted at $55^{\circ} \mathrm{C}$ with $0.13 \mathrm{M}$ sodium citrate buffer adjusted to $\mathrm{pH} 5.25$ with conc. $\mathrm{HCl}$.

For identification, the amino sugars were eluted from a column $(1 \mathrm{~cm} \times 30 \mathrm{~cm})$ of Amerlite CG-120 resin (200 mesh) at $50^{\circ} \mathrm{C}$ with $0.35 \mathrm{M}$-sodium citrate buffer, pH 5.26 (Partridge \& Elsden, 1961). Pooled fractions were desalted on a column $(6 \mathrm{~cm} \times 2 \mathrm{~cm})$ of Dowex 50 resin $\left(\mathrm{H}^{+}\right.$ form) and the hexosamines were degraded to the corresponding pentoses with ninhydrin (Stoffyn \& Jeanloz, 1954).

$\mathrm{N}$-Acetylhexosamines. Ovomucin complex $(20 \mathrm{mg})$ was hydrolysed with $0.1 \mathrm{M}-\mathrm{HCl}(5 \mathrm{ml})$ at $100^{\circ} \mathrm{C}$ for up to $6 \mathrm{~h}$. Samples $(0.25 \mathrm{ml})$ were taken at $1 \mathrm{~h}$ intervals and tested for $N$-acetylhexosamine by the method of Reissig, Strominger \& Leloir (1955). For identification by paper chromatography ovomucin complex (approx. $10 \mathrm{mg}$ ) was hydrolysed in $0.1 \mathrm{M}-\mathrm{HCl}(1 \mathrm{ml})$ at $100^{\circ} \mathrm{C}$ for $5 \mathrm{~h}$, and the hydrolysate was neutralized with $0.1 \mathrm{M}-\mathrm{NaOH}$ and desalted on a column $(28 \mathrm{~cm} \times 2.4 \mathrm{~cm})$ of Sephadex G-10, which was eluted with water. The desalted extracts were concentrated by evaporation before paper chromatography.

Sialic acids. Quantitative determination of the total sialic acid content was performed by the thiobarbituric acid procedure (Warren, 1959) after hydrolysis of samples $(4 \mathrm{mg})$ with $50 \mathrm{~mm}-\mathrm{H}_{2} \mathrm{SO}_{4}(2 \mathrm{ml})$ at $80^{\circ} \mathrm{C}$ for $1 \mathrm{~h}$. For identification of the released sialic acid, ovomucin complex $(20 \mathrm{mg})$ was hydrolysed with $50 \mathrm{~mm}-\mathrm{H}_{2} \mathrm{SO}_{4}(4 \mathrm{ml})$ at $80^{\circ} \mathrm{C}$ for $1 \mathrm{~h}$. Then the acid was neutralized with a saturated solution of $\mathrm{Ba}(\mathrm{OH})_{2}$ and the supernatant freeze-dried. Sialic acids were extracted from the dry residue with methanol $(80 \%, v / v)$ before paper chromatography. The presence of $N$-glycollylneuraminic acid was also tested for by hydrolysing ovomucin complex $(20 \mathrm{mg})$ with $0.5 \mathrm{M}-\mathrm{H}_{2} \mathrm{SO}_{4}(4 \mathrm{ml})$ for $1 \mathrm{~h}$ at $100^{\circ} \mathrm{C}$ and testing for glycollic acid by the method of Klenk \& Uhlenbruck (1957). $N$-Acetylneuraminic acid and $N$-glycollylneuraminic acid were used as standards.

Amino acids. Dry samples $(4 \mathrm{mg}$ ) were hydrolysed at $110^{\circ} \mathrm{C}$ for various times with constant-boiling $\mathrm{HCl}(4 \mathrm{ml})$ in sealed evacuated tubes. Acid was removed by evaporation and amino acid analyses were carried out with a Beckman 120C amino acid analyser. Trytophan was determined in unhydrolysed samples by the method of Spies \& Chambers (1949).

Sulphate. Ester sulphate was determined after hydrolysis in $6 \mathrm{M}$-formic acid at $100^{\circ} \mathrm{C}$ for $9 \mathrm{~h}$ by the method of Jones \& Lethan (1956).

Other analyses. Tests for uronic acids and fucose were carried out by the methods of Bitter \& Ewins (1961) and Dische \& Shettles (1948) respectively. Protein was determined by measuring the extinction at $276 \mathrm{~nm}$.

Paper chromatography. Descending chromatography was used. For qualitative analysis hexoses were chromatographed for $20 \mathrm{~h}$ at $20^{\circ} \mathrm{C}$ with the organic phase of ethyl acetate-acetic acid-water $(3: 1: 3$, by vol.), ethyl acetatepyridine-water (5:2:5, by vol.), butan-1-ol-pyridinewater $(9: 5: 8$, by vol.) or sym-collidine saturated with water. Hexoses were detected with the alkaline- $\mathrm{AgNO}_{3}$ method (Bezkorovainy, 1963) and the aniline hydrogen phthalate method of Partridge (1949). To detect galactose or to confirm the absence of glucose, the dried chromato. grams were sprayed with either Galactostat or Glucostat reagents (Salton, 1960) prepared for quantitative determination of the hexoses as recommended by the manufacturers. For quantitative analysis of hexoses chromatography was with the organic phase of ethyl acetate-acetic acid-water (3:1:3, by vol.) for $40 \mathrm{~h}$ at $20^{\circ} \mathrm{C}$. The $R_{\text {Gic }}$ values were 0.78 for galactose, 1.33 for mannose and 2.48 for fucose. $N$-Acetylhexosamines were chromatographed on Whatman no. 1 paper treated with $0.2 \mathrm{~m}$-sodium borate buffer, $\mathrm{pH}$ 8.0, with the organic phase of either ethyl acetate-acetic acid-water (3:1:3, by vol.) for $15 \mathrm{~h}$ or ethyl acetate-pyridine-water $(2: 1: 2$, by vol.) for $24 \mathrm{~h}$. $N$-Acetylglucosamine and $N$-acetylgalactosamine were separated from glucosamine, galactose, mannose and $N$-acetylneuraminic acid. For detection of the $N$-acetylhexosamines the alkaline- $\mathrm{AgNO}_{3}$ method was used. Sialic acids were chromatographed on Whatman no. 1 paper with butan-1-ol-propan-1-ol-0.1 M-HCl (1:2:1, by vol.) (Svennerholm \& Svennerholm, 1958) to distinguish betweon $N$-acetylneuraminio acid and $N$. 
glycollylneuraminic acid. The organic phase of butan-1ol-acetic acid-water (4:1:5, by vol.) was used to distinguish between $N$-acetylneuraminic acid and $N O$-diacetylneuraminic acid (Whitehouse \& Zilliken, 1960). A thiobarbituric acid spray reagent (Warren, 1960) and an alkaline $\mathrm{AgNO}_{3}$ spray reagent (Bezkorovainy, 1963) were used to detect sialic acids. Butan-1-ol-pyridine-water $(6: 4: 3$, by vol.) (Blix \& Lindberg, 1960) and the organic phase of ethyl acetate-acetic acid-water (3:1:3, by vol.) were also used to compare the released $\mathrm{AgNO}_{3}$-reactive components with markers of galactose and mannose.

Aas-liquid chromatography. For determination of bexoses by g.l.c., samples $(2 \mathrm{mg})$ were hydrolysed in dry methanolic $\mathrm{l} \mathrm{M}-\mathrm{HCl}$ for $24 \mathrm{~h}$ at $80^{\circ} \mathrm{C}$ and then neutralized with $\mathrm{AgCO}_{3}$ as described by Clamp, Dawson \& Hough (1967). Methanol was removed by evaporation and the residues were silylated with $100 \mu$ l of Tri-Sil Z. A $1 \mu l$ sample of silylation mixture was injected into a glass column $(2.74 \mathrm{~m} \times 6.3 \mathrm{~mm})$ containing SE-54 $(3 \%, \mathrm{w} / \mathrm{w})$ on CQ support. A series 104 (W. G. Pye Ltd.) gas chromatograph fitted with dual-flame ionization detectors was held at $130^{\circ} \mathrm{C}$ for $20 \mathrm{~min}$ and then temperature-programmed at $\frac{1}{2}^{\circ} \mathrm{C} / \mathrm{min}$ to $200^{\circ} \mathrm{C}$. The programme rate of $\frac{1}{2}^{\circ} \mathrm{C} / \mathrm{min}$ was necessary to resolve all the isomers of silylated methyl glycosides of mannose and galactose. For this purpose a gear train (with ratio of $90000: 1$, obtained from W. G. Pye Ltd.) was fitted to the temperature programmer. Argon was used as the carrier gas at a flow rate of $45 \mathrm{ml}$ / min after prepurification over a molecular sieve of Linde 5A.

Reduction of the purified ovomucin complex. A $2.5 \mathrm{ml}$ portion of $0.5 \mathrm{M}$-tris-HCl buffer, pH 8.2, containing $0.3 \mathrm{M}$ mercaptoethanol and $6 \mathrm{M}$-guanidine hydrochloride was used to reduce the purified ovomucin complex $(50 \mathrm{mg})$ at $20^{\circ} \mathrm{C}$ for $16 \mathrm{~h}$. The thiol groups were alkylated by the addition of $1 \mathrm{M}$-tris $(2.5 \mathrm{ml})$ containing $4 \mathrm{M}$-guanidine hydrochloride and $0.36 \mathrm{~m}$-iodoacetic acid (Small \& Lamm, 1966) for $1 \mathrm{~h}$.

Gel filtration. Samples that had been reduced with mercaptoethanol and alkylated with iodoacetic acid were dialysed against either $6 \mathrm{M}$-urea or $6 \mathrm{M}$-guanidine hydrochloride. Columns $(91 \mathrm{~cm} \times 2.5 \mathrm{~cm})$ of Sephadex G-200, Sepharose 2B or Sepharose 4B were used, and eluted with either $6 \mathrm{M}$-urea or $6 \mathrm{M}$-guanidine hydrochloride.

Electrophoresis. This was carried out on cellulose acetate strips (Phoroslides, $7.5 \mathrm{~cm} \times \mathbf{2 . 5} \mathrm{cm}$; Millipore Corp., Bedford, Mass., U.S.A.) at $100 \mathrm{~V}$ for $20 \mathrm{~min}$. The buffer solution used contained diethylbarbituric acid $(0.331 \mathrm{~g})$, sodium diethylbarbiturate $(1.848 \mathrm{~g})$ and water $(120 \mathrm{ml})$ at $\mathrm{pH} 8.6(I 0.075)$. The strips were subsequently stained for $10 \mathrm{~min}$ with either Alcian Blue $8 \mathrm{GX}(1 \%$, $\mathrm{w} / \mathrm{v})$ in acetic acid $(5 \%, v / v)$ or with Millipore Ponceau $S$ concentrate $(2 \mathrm{ml})$ diluted with water $(38 \mathrm{ml})$. Excess of stain was removed in acetic acid $(5 \%, v / v)$ and the strips were air-dried.

Analytical sedimentation in density gradients. This was performed in a Beckman-Spinco model $\mathbf{E}$ analytical ultracentrifuge fitted with electronic speed control in $12 \mathrm{~mm}$ cells. The speed was $40000 \mathrm{rev} . / \mathrm{min}$. The temperature was controlled at $25^{\circ} \mathrm{C}$ with the RTIC unit. The solutions contained $4 \mathrm{M}$-guanidine hydrochloride, 0.1 M-sodium acetate adjusted to $\mathrm{pH} 4.8$ with $0.1 \mathrm{M}$-acetic acid, and CsCl. The initial concentration of reduced-alkylated ovomucin complex was approx. $2 \mathrm{mg} / \mathrm{ml}$. Densities were measured in $0.2 \mathrm{ml}$ constriction pipettes at room temperature.

Preparative sedimentation in density gradients. Reduced ovomucin complex $(250 \mathrm{mg})$ alkylated with iodoacetic acid was dissolved in $4 \mathrm{M}$-guanidine hydrochloride $(60 \mathrm{ml})$ containing $\mathrm{CsCl}$ at a required density of $1.33 \mathrm{~g} / \mathrm{ml}$.

The solutions were centrifuged in an MSE Superspeed 50 ultracentrifuge (rotor no. 2418) at $28000 \mathrm{rev} . / \mathrm{min}$. at $25^{\circ} \mathrm{C}$ for $72 \mathrm{~h}$. The polypropylene tubes $(6.9 \mathrm{~cm} \times 2.1 \mathrm{~cm})$, after deceleration (without brake), were removed and pierced at the bottom and the contents collected in eight $2.5 \mathrm{ml}$ fractions. Samples from each fraction were used for measurement of density and $E_{276}$. After dialysis of the fractions against $0.1 \mathrm{M}-\mathrm{Na}_{2} \mathrm{SO}_{4}$ hexoses were determined with the anthrone reagent. When a BeckmanSpinco model L ultracentrifuge (rotor SW 39) was used ultracentrifugation was in polypropylene tubes $(5.1 \mathrm{~cm} \times$ $1.3 \mathrm{~cm}$ ) at $35000 \mathrm{rev} . / \mathrm{min}$ at $25^{\circ} \mathrm{C}$ for $72 \mathrm{~h}$.

Analytical sedimentation. Equilibrium sedimentation was performed in a Beckman-Spinco model $\mathbf{E}$ analytical ultracentrifuge fitted with Rayleigh optics in a doublesector interference cell under conditions suggested by Yphantis (1964) to determine weight-average molecular weights. The freeze-dried material $(0.2 \mathrm{mg})$ was dissolved in $5 \mathrm{M}$-guanidine hydrochloride $(0.5 \mathrm{ml})$ and dialysed against $5 \mathrm{M}$-guanidine hydrochloride for $24 \mathrm{~h}$ at $0^{\circ} \mathrm{C}$. The density of $5 \mathrm{M}$-guanidine hydrochloride at $22^{\circ} \mathrm{C}$ was $1.1222 \mathrm{~g} / \mathrm{ml}$.

Separate velocity-sedimentation measurements were carried out by using schlieren optics. Before the centrifugation, the materials were dialysed against a phosphate buffer (10 mM- $\mathrm{NaH}_{2} \mathrm{PO}_{4}$ adjusted to $\mathrm{pH} 7.4$ with $10 \mathrm{~mm}$ $\mathrm{Na}_{2} \mathrm{HPO}_{4}$ ) containing $0.1 \mathrm{M}-\mathrm{NaCl}, 5 \mathrm{M}$-urea or $5 \mathrm{M}$ guanidine hydrochloride. Cells with $30 \mathrm{~mm}$ aluminium centre-pieces were used in an An-E rotor at $40000 \mathrm{rev}$./ min. The camera lens was focused at the midpoint of the long-path length cells. Sedimentation coefficients were determined by the rapid method described by Markham (1960). Densities and viscosities of guanidine hydrochloride at $25^{\circ} \mathrm{C}$ were obtained from Kawahara \& Tanford (1966).

Alkali-induced $\beta$-elimination. Samples (16 mg) were suspended in $0.5 \mathrm{M}-\mathrm{NaOH}(3 \mathrm{ml})$ and stirred under $\mathrm{N}_{2}$ at $20-22^{\circ} \mathrm{C}$. After $22 \mathrm{~h}$ the alkaline solution was made up to $5 \mathrm{ml}$ with water and portions $(1 \mathrm{ml})$ were added to constant boiling. $\mathrm{HCl}(5 \mathrm{ml})$ and hydrolysed as described for amino acids. Further samples $(1 \mathrm{ml})$ were added to $4 \mathrm{M}-\mathrm{HCl}(5 \mathrm{ml})$ and hydrolysed as described for hexosamines. The molar ratios of glucosamine and galactosamine were determined with the use of the Beckman 120C amino acid analyser as described above for the determination of hexosamines.

\section{RESULTS}

The amount of insoluble purified ovomucin complex was found to be equivalent to $0.2 \%$ (w/w) of the total thick egg-white fraction. After reduction and alkylation of the ovomucin complex a clear non-viscous solution was obtained for gel filtration, electrophoresis and ultracentrifugation.

Gel filtration. The reduced ovomucin complex was eluted with either $6 \mathrm{M}$-urea or $6 \mathrm{M}$-guanidine 


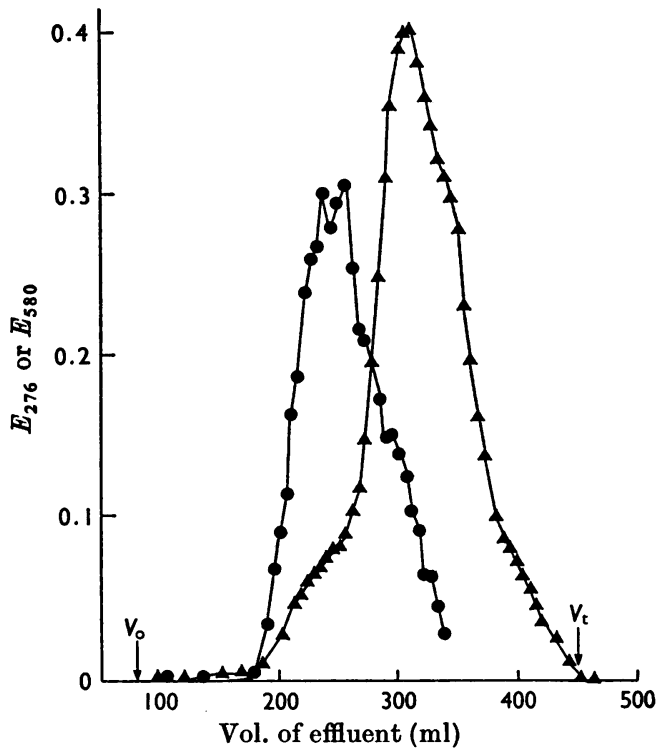

Fig. 1. Chromatography with $6 \mathrm{~m}$-guanidine hydrochloride on Sepharose 2B of reduced ovomucin complex $(100 \mathrm{mg})$. Samples from each tube were assayed for sialic acids ( $\bullet$ ) and protein $(\Delta)$.

hydrochloride from columns of Sephadex G-200 at the void volume of the column as a symmetrical peak. As none of the applied sample, as judged by $E_{276}$ and reaction of samples of the column effluent with anthrone reagent, was retarded by the Sephadex G-200 gel there was no evidence of fractionation on Sephadex G-200. However, gel filtration on columns of Sepharose $2 B$ in the presence of $6 \mathrm{M}$-guanidine hydrochloride showed the presence of two fractions, one of which was mainly protein whereas the other contained larger amounts of resorcinol-reactive substances (Svennerholm, 1957) (Fig. 1). When 6M-guanidine hydrochloride was replaced by $6 \mathrm{M}$-urea no separation of the protein and the resorcinol-reactive components was observed.

Electrophoresis. Electrophoresis on cellulose acetate strips of the reduced ovomucin complex resulted in a partial separation of acidic Alcianophilic substances from a single protein band. As the faster-migrating Alcianophilic substances were not present in samples of the reduced ovomucin complex that had been treated with neuraminidase it seemed that electrophoresis was separating sialic acid-rich components. However, subsequent attempts to fractionate protein and sialic acid-rich components present in the preparations of reduced ovomucin complex with a Hannig continuous electrophoretic separator (Hannig, 1964) were

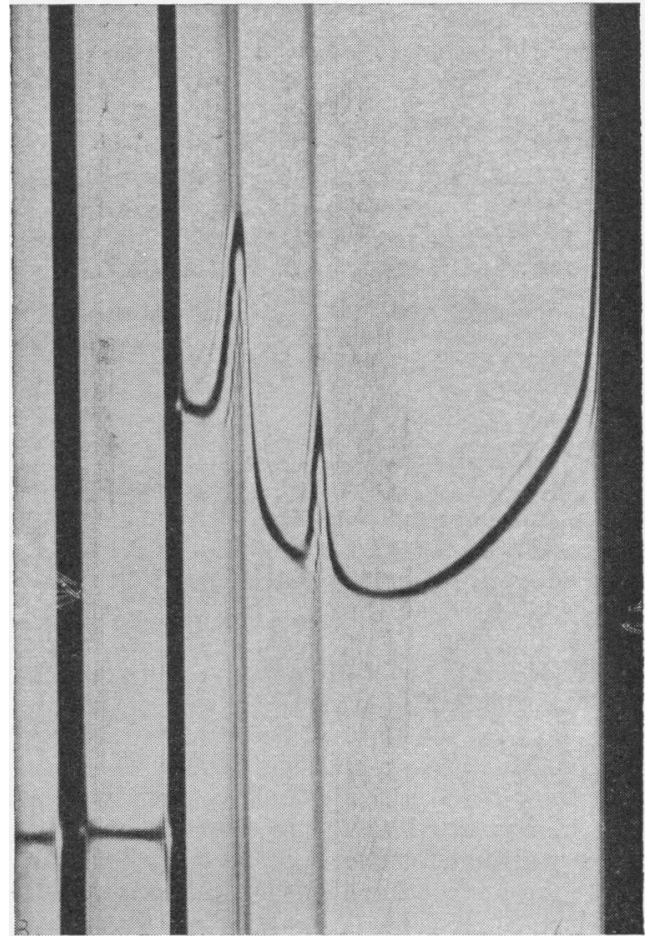

Fig. 2. Sedimentation-velocity experiments with reduced ovomucin complex $(0.5 \%, \mathrm{w} / \mathrm{v})$ in $5 \mathrm{M}$-guanidine hydrochloride. Frames were recorded after $103 \mathrm{~min}$ at 40000 $\mathrm{rev} / \mathrm{min}$. The temperature was $25^{\circ} \mathrm{C}$.

unsuccessful; occasionally a partial separation of protein and resorcinol-reactive components was achieved. Disc electrophoresis with polyacrylamide gels $(2.5 \%, \mathrm{w} / \mathrm{v})$ in the presence of $6 \mathrm{M}$-urea was also unsuccessful; staining with either Amido Black or Alcian Blue showed that the reduced ovomucin complex remained at the top of the gel columns.

Ultracentrifugation. Fig. 2 shows the analytical sedimentation-velocity pattern of the reduced ovomucin complex in the presence of $5 \mathrm{M}$-guanidine hydrochloride. As determined by triangulation of the peaks the slower-sedimenting component $(2.7 \mathrm{~S})$ contained approx. $65 \%$ of the reduced ovomucin complex and the faster-sedimenting component (5.8S) approx. $35 \%$ of the reduced ovomucin complex. As reported previously (Robinson \& Monsey, 1966) sedimentation in 6M-urea only showed one schlieren peak (5.6S) at a concentration of $0.5 \%(\mathrm{w} / \mathrm{v})$ at $25^{\circ} \mathrm{C}$. Sedimentation in the phosphate buffer, pH 7.5, containing up to $2 \mathrm{M}$-sodium chloride showed mainly one schlieren peak $(10.6 \mathrm{~S})$ and two minor schlieren peaks (6.2S and 13.3S) at a concentration of $0.3 \%(w / v)$ at $20^{\circ} \mathrm{C}$. 


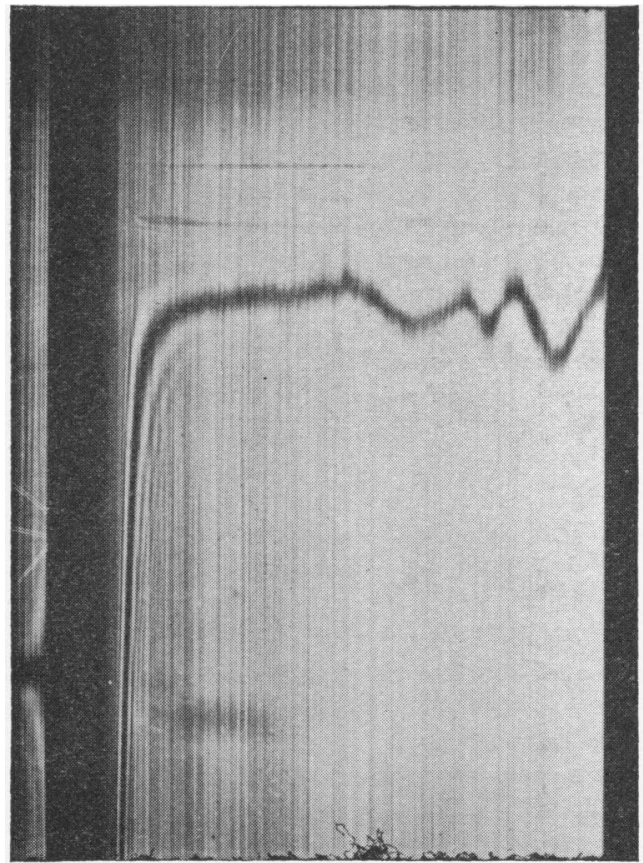

Fig. 3. Analytical density-gradient experiments on reduced ovomucin complex in $4 \mathrm{~m}$-guanidine hydrochloride and $\mathrm{CsCl}$ after $18 \mathrm{~h}$ at $40000 \mathrm{rev} . / \mathrm{min}$. The concentration was $2 \mathrm{mg} / \mathrm{ml}$. The initial density was $1.42 \mathrm{~g} / \mathrm{ml}$. The temperature was $25^{\circ} \mathrm{C}$.

Fig. 3 shows a typical schlieren pattern obtained by sedimentation equilibrium in a density gradient of caesium chloride in the presence of $4 \mathrm{M}$-guanidine hydrochloride. A low-density fraction accumulated at the meniscus, and higher-density fractions, containing three components, accumulated towards the middle of the cell. Preparative density-gradient experiments carried out in the MSE Superspeed 50 preparative ultracentrifuge showed that proteinrich substances could be separated from carbohydrate-rich components (Fig. 4). The hexose-rich and protein-rich fractions were pooled separately and freeze-dried after extensive dialysis against water at $0^{\circ} \mathrm{C}$. The protein-rich fraction (now designated reduced $\alpha$-ovomucin) was redissolved in $4 \mathrm{M}$-guanidine hydrochloride $(15 \mathrm{ml})$ containing caesium chloride at a required density of $1.33 \mathrm{~g} / \mathrm{ml}$ and further purified by centrifugation in a Beckman-Spinco model L ultracentrifuge (rotor no. SW 39) at $35000 \mathrm{rev} \cdot / \mathrm{min}$ at $25^{\circ} \mathrm{C}$ for $72 \mathrm{~h}$. The hexose-rich fraction (now designated reduced $\beta$ ovomucin) was redissolved in $4 \mathrm{M}$-guanidine hydrochloride $(15 \mathrm{ml})$ containing caesium chloride at a required density of $1.34 \mathrm{~g} / \mathrm{ml}$ and centrifuged in the Beckman-Spinco model L centrifuge as described

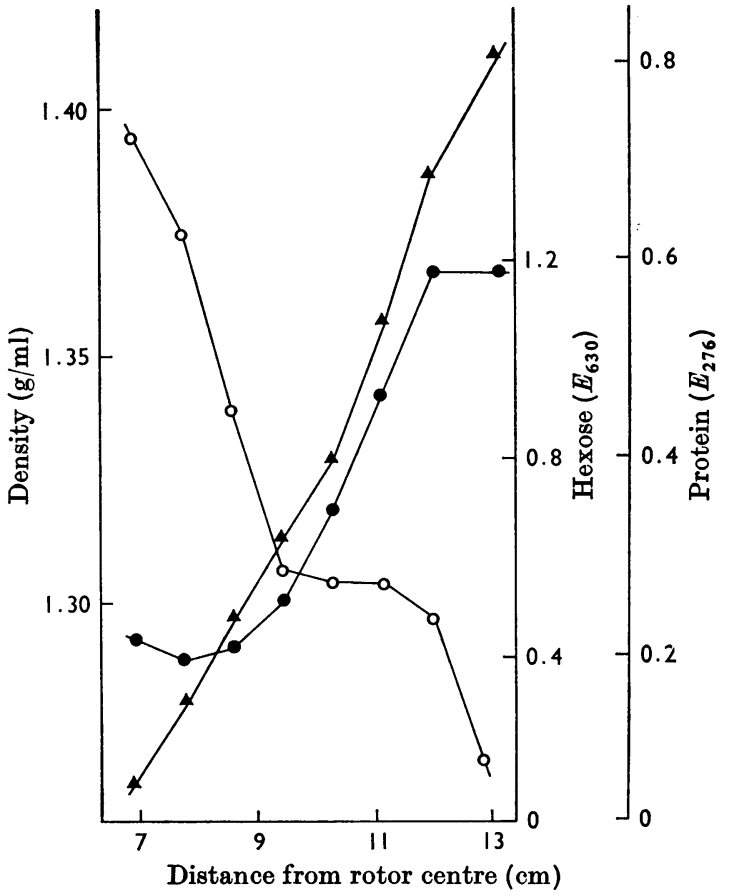

Fig. 4. Preparative density-gradient experiment on reduced ovomucin complex. The tubes were fractionated into eight samples of equal volume, whose density $(\boldsymbol{\Delta})$ was determined. After removal of the $\mathrm{CsCl}$ and guanidine hydrochloride by dialysis the samples were assayed for hexose sugar (0) and protein (O).

above. Fractions $(0.5 \mathrm{ml})$ were collected and analysed as described above for protein and hexoses. Reduced $\alpha$-ovomucin $(50 \mathrm{mg})$ and reduced $\beta$-ovomucin (60 mg) fractions were recovered.

Figs. 5 $(a)$ and 5(b) show the analytical-sedimentation-equilibrium patterns in density gradients of caesium chloride obtained for the isolated reduced $\alpha$-ovomucin and $\beta$-ovomucin fractions in solutions containing $4 \mathrm{M}$-guanidine hydrochloride with initial densities of $1.305 \mathrm{~g} / \mathrm{ml}$ and $1.425 \mathrm{~g} / \mathrm{ml}$ respectively. The reduced $\beta$-ovomucin fraction is clearly heterogeneous, whereas the reduced $\alpha$-ovomucin appears to be homogeneous. Both the isolated reduced $\alpha$-ovomucin and $\beta$-ovomucin fractions showed single symmetrical schlieren peaks $\left(s_{20, w} 4.1 \mathrm{~S}\right.$ and 8.9S respectively) when subjected to analytical sedimentation-velocity experiments at a concentration of $0.3 \%(\mathrm{w} / \mathrm{v})$ at $25^{\circ} \mathrm{C}$ in the presence of 5 M-guanidine hydrochloride. Partial specific volumes, $\bar{v}$, of 0.701 and 0.649 were calculated from the composition of reduced $\alpha$-ovomucin and $\beta$ ovomucin fractions respectively and reduced by $0.01 \mathrm{ml} / \mathrm{g}$ to take account for the effect of guanidine 
hydrochloride on the partial specific volume of proteins (Tanford, Kawahara \& Lapanje, 1967). A weight-average molecular weight of 210000 was calculated from the Rayleigh interference patterns of the equilibrium-sedimentation experiments with the isolated reduced $\alpha$-ovomucin fraction in $5 \mathrm{M}$ guanidine hydrochloride. Equilibrium was established at $16300 \mathrm{rev} \cdot / \mathrm{min}$ at $22^{\circ} \mathrm{C}$ within $27 \mathrm{~h}$. Analytical sedimentation-velocity experiments with the isolated reduced $\alpha$-ovomucin and $\beta$-ovomucin fractions at concentrations of $0.3 \%(w / v)$ in the phosphate buffer, pH 7.5, containing 0.1 M-sodium chloride showed multiple schlieren peaks $\left(s_{20, w}\right.$ 6.8S, $11.7 \mathrm{~S}$ and $14.7 \mathrm{~S}$ for $\alpha$-ovomucin and $s_{20}$,w 6.5S to $16.2 \mathrm{~S}$ for $\beta$-ovomucin), which are attributed to aggregation in the absence of guanidine hydrochloride.
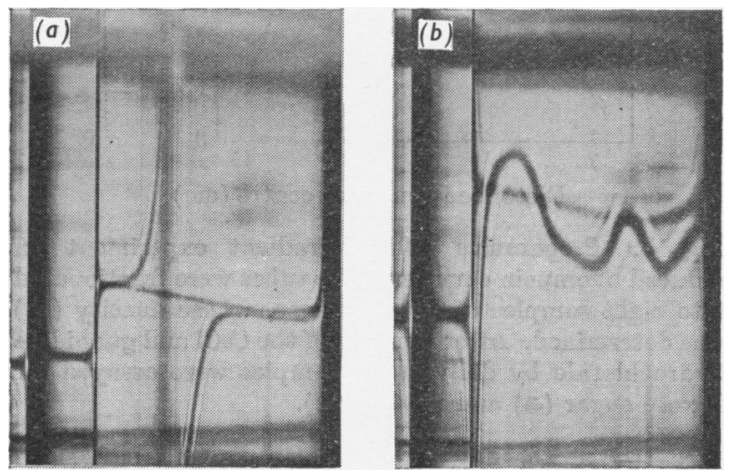

Fig. 5. Analytical density-gradient experiments on the glycoprotein fractions from reduced ovomucin complex in $4 \mathrm{M}$-guanidine hydrochloride and $\mathrm{CsCl}$ at $25^{\circ} \mathrm{C}$. (a) Reduced $\alpha$-ovomucin $(1.5 \mathrm{mg} / \mathrm{ml})$, initial density $1.305 \mathrm{~g} /$ $\mathrm{ml}$, after $18 \mathrm{~h}$ at $40000 \mathrm{rev} . / \mathrm{min}$. (b) Reduced $\beta$-ovomucin fraction $(3 \mathrm{mg} / \mathrm{ml})$, density $1.425 \mathrm{~g} / \mathrm{ml}$, after $18 \mathrm{~h}$ at $40000 \mathrm{rev} . / \mathrm{min}$.
Carbohydrate analysis. The maximal release of hexoses from the ovomucin complex as judged by the anthrone procedure was found after hydrolysis for $2 \mathrm{~h}$ in $1 \mathrm{M}$-hydrochlorio acid at $100^{\circ} \mathrm{C}$. Galactose and mannose were observed on paper chromatograms and their identities confirmed after reaction of the water-eluted substances with the cysteinesulphuric acid reagent. Fucose was not detected on paper chromatograms or by colorimetric analysis. The charts obtained from the gas chromatograph also showed fucose to be absent.

The maximal release of glucosamine and galactosamine from the ovomucin complex was found after hydrolysis for $4 \mathrm{~h}$ in $4 \mathrm{M}$-hydrochloric acid at $100^{\circ} \mathrm{C}$. The elution from the Amberlite resin CG-120 of Elson-Morgan-reactive substances at the volumes required for elution of authentic samples of glucosamine and galactosamine, and the occurrence of arabinose and lyxose after ninhydrin degradation of the desalted fractions, was taken as evidence for the presence of glucosamine and galactosamine in the hydrolysates.

The hexosamines were probably present as the $\mathrm{N}$-acetyl derivatives, as indicated by detection of these compounds by the procedure of Reissig et al. (1955). The maximal release of $N$-acetylhexosamines was found after a $5 \mathrm{~h}$ hydrolysis in $0.1 \mathrm{M}$ hydrochloric acid at $100^{\circ} \mathrm{C}$. Ovomucin complex was found to contrin a measured $8.0 \%(\mathrm{w} / \mathrm{w})$ of $N$. acetylhexosamine. However, $46 \%(w / w)$ of a standard solution $\mathrm{N}$-acetylglucosamine was destroyed during heating at $100^{\circ} \mathrm{C}$ in $0.1 \mathrm{M}$-hydrochloric acid for $5 \mathrm{~h}$. Paper chromatography of acid hydrolysates of the ovomucin complex that had been desalted on columns of Sephadex G-100 showed the presence of both $N$-acetylglucosamine and $N$-acetylgalactosamine.

Almost all the sialic acid $(95 \%, \mathrm{w} / \mathrm{w})$ as determinted by the Warren (1959) procedure was released from the ovomucin complex in $30 \mathrm{~min}$ on hydrolysis by 50 mM-sulphuric acid (Fig. 6a).
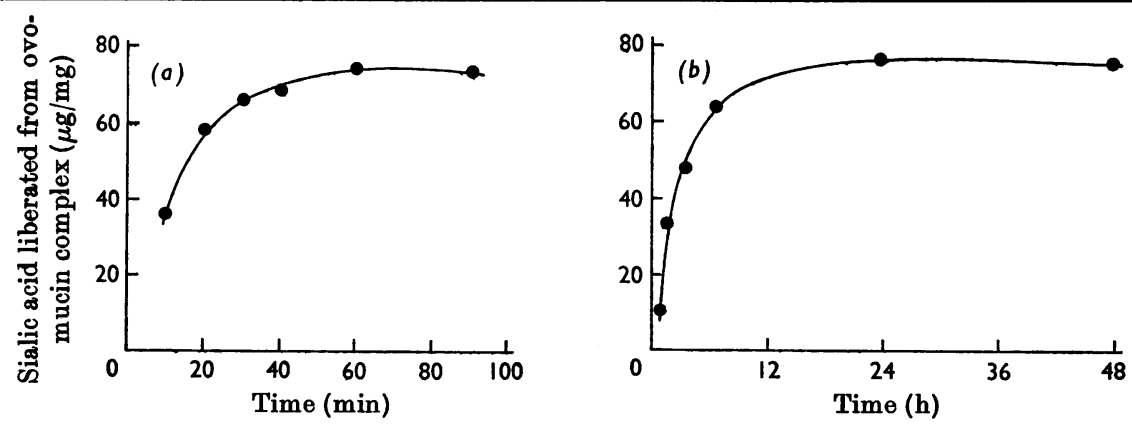

Fig. 6. Rate of liberation of sialic acid. (a) Ovomucin complex $(5 \mathrm{mg} / \mathrm{ml})$ hydrolysed in $50 \mathrm{~mm}_{-} \mathrm{H}_{2} \mathrm{SO}_{4}$ at $80^{\circ} \mathrm{C}$. (b) Ovomucin complex $(5 \mathrm{mg} / \mathrm{ml})$ incubated with neuraminidase at $37^{\circ} \mathrm{C}$. Sialic acid was determined by the thiobarbituric acid method. 
Table 1. Composition of ovomucin

The preparations used were: (1) dry ovomucin complex, ash content $2.1 \%(w / w)$; (2) dry reduced $\alpha$-ovomucin; (3) dry reduced $\beta$-ovomucin fraction.

\begin{tabular}{|c|c|c|c|c|c|}
\hline \multicolumn{6}{|c|}{ Composition } \\
\hline \multicolumn{3}{|c|}{$(g / 100 g)$} & \multicolumn{3}{|c|}{ (mol/105 $\mathrm{g}$ of sample) } \\
\hline (1) & (2) & (3) & (1) & (2) & (3) \\
\hline 60.6 & 69.5 & 28.1 & - & - & - \\
\hline 8.0 & 6.7 & 11.0 & 36.0 & 30.1 & 49.7 \\
\hline 4.0 & 0.6 & 8.7 & 18.0 & 2.8 & 39.2 \\
\hline 8.5 & 1.8 & 19.2 & 47.2 & 10.0 & 106.5 \\
\hline 2.8 & 4.6 & 4.1 & 15.5 & 25.5 & 22.8 \\
\hline 7.4 & 1.0 & 13.8 & 23.9 & 3.2 & 44.7 \\
\hline 1.4 & 0.7 & 2.7 & 14.6 & 7.3 & 28.1 \\
\hline 0.03 & - & - & - & - & - \\
\hline 92.7 & 84.9 & 87.6 & & & \\
\hline
\end{tabular}

Table 2. Carbohydrates of egg-white glycoproteins

Protein (from Table 2)

$N$-Acetylglucosamine

$N$-Acetylgalactosamine

Galactose

Mannose

Total sialic acid (Warren, 1959)

Sulphate

Phosphate

Total
Carbohydrate composition $(\mathrm{g} / 100 \mathrm{~g})$

\begin{tabular}{|c|c|c|c|c|c|}
\hline Glucosamine & $\begin{array}{l}\text { Galactos- } \\
\text { amine }\end{array}$ & Galactose & Mannose & $\begin{array}{l}\text { Sialic } \\
\text { acid }\end{array}$ & Reference \\
\hline 1.2 & 0 & 0 & $1.7-2.0$ & 0 & Parkinson (1966) \\
\hline $12-14$ & 0 & 1.5 & 4-6 & $0.4-4.0$ & Parkinson (1966) \\
\hline 1.8 & 0 & 0 & 0.9 & 0 & Williams (1968) \\
\hline 5.4 & 0.5 & 1.8 & 4.6 & 1 & This paper \\
\hline 8.8 & 7.0 & 19.2 & 4.1 & 13.8 & This paper \\
\hline 5.5 & 0 & \multicolumn{2}{|c|}{0.3} & 0 & Donovan et al. (1970) \\
\hline $2.8-5.6$ & $\mathbf{0}$ & 0 & $2.1-3.7$ & $0.1-0.3$ & $\begin{array}{c}\text { Davis, Zahnley \& } \\
\text { Donovan (1969) }\end{array}$ \\
\hline 13.8 & $\mathbf{0}$ & 4.5 & 9.0 & 3.0 & Ketterer (1965) \\
\hline 3.8 & $\mathbf{0}$ & 0 & 5.8 & 0 & $\begin{array}{l}\text { Melamed \& Green } \\
\text { (1963) }\end{array}$ \\
\hline
\end{tabular}

Neuraminidase $(0.3 \mathrm{mg})$ dissolved in $30 \mathrm{~mm}$-trismalate buffer, pH6.5 (12 ml), containing 6mMcalcium chloride liberated sialic acid $(97 \%, w / w)$ in $6 \mathrm{~h}$ at $37^{\circ} \mathrm{C}$ (Fig. $6 b$ ). The sialic acid present in the hydrolysates and neuraminidase digests of the ovomucin complex was found by paper chromatography to be $N$-acetylneuraminic acid. Glycollic acid was not detected in the acid hydrolysates of the ovomucin complex, and substances corresponding chromatographically in $R_{F}$ value to $N$ glycollylneuraminic acid or $\mathrm{NO}$-diacetylneuraminic acid were not found in extracts of the hydrolysate and neuraminidase digests of ovomucin complex.

The results of the quantitative carbohydrate analysis for the ovomucin complex, reduced $\alpha$ ovomucin and the reduced $\beta$-ovomucin fractions are given in Table 1. The monosaccharides present in the carbohydrate moieties of $\alpha$-ovomucin and $\beta$-ovomucin and other characterized egg-white glycoproteins are presented in Table 2 for purposes of comparison.

Amino acid composition. For maximum recovery of amino acids, $20 \mathrm{~h}$ at $110^{\circ} \mathrm{C}$ was found to be optimum for hydrolysis of the ovomucin complex in constant-boiling hydrochloric acid. The rates of destruction of threonine and serine during a $20 \mathrm{~h}$ hydrolysis were $3.46 \%(w / w)$ and $7.17 \%(w / w)$ respectively. The amino acid analysis of the purified preparation of ovomucin complex and reduced $\alpha$-ovomucin and $\beta$-ovomucin is given in Table 3. Amino acid analysis of the reduced $\alpha$-ovomucin and $\beta$-ovomucin showed the presence of $S$-carboxymethylcysteine and the absence of cystine. Glutamic acid and aspartic acid were the major amino acids in the reduced $\alpha$-ovomucin preparation, whereas serine and threonine were the 
Table 3. Amino acid analysis of ovomucin

The preparations used were: (1) dry ovomucin complex; (2) dry reduced $\alpha$-ovomucin; (3) dry reduced $\beta$-ovomucin.

\begin{tabular}{|c|c|c|c|c|c|c|}
\hline & \multicolumn{6}{|c|}{ Amino acid composition } \\
\hline & \multicolumn{3}{|c|}{$\begin{array}{l}\text { (g of anhydro amino acid/100 } \mathrm{g} \text { of } \\
\text { dry sample) }\end{array}$} & \multicolumn{3}{|c|}{ (mol/10 $\mathrm{g}$ of total protein) } \\
\hline & (1) & (2) & (3) & (1) & $(2)$ & (3) \\
\hline Lysine & 4.3 & 4.3 & 1.6 & 55.3 & 48.2 & 44.5 \\
\hline Ammonia & 1.7 & 1.6 & 1.6 & & & \\
\hline Histidine & 1.7 & 1.7 & 0.6 & 20.5 & 18.0 & 14.9 \\
\hline Arginine & 2.6 & 2.6 & 1.0 & 27.7 & 23.7 & 22.8 \\
\hline Aspartic acid & 5.6 & 6.9 & 2.0 & 80.5 & 86.3 & 63.0 \\
\hline Threonine* & 4.6 & 4.6 & 3.3 & 74.4 & 65.5 & 117.0 \\
\hline Serine* & 4.3 & 4.3 & 3.1 & 81.7 & 71.1 & 126.0 \\
\hline Glutamic acid & 7.0 & 9.0 & 2.7 & 89.8 & 100.0 & 75.5 \\
\hline Proline & 3.3 & 3.2 & 1.8 & 56.8 & 47.5 & 65.1 \\
\hline Glycine & 1.8 & 2.4 & 0.7 & 52.0 & 59.7 & 40.2 \\
\hline Alanine & 1.8 & 2.1 & 1.1 & 41.8 & 42.4 & 56.2 \\
\hline Valine & 3.3 & 3.7 & 1.2 & 54.3 & 53.2 & 43.4 \\
\hline Cystine (half) & $4.1 \dagger$ & $5.7 \ddagger$ & $1.4 \ddagger$ & $63.7 \dagger$ & $76.2 \ddagger$ & 47.0 \\
\hline Methionine & 1.4 & $1.1^{\star}$ & 0.5 & 18.0 & 7.2 & 12.4 \\
\hline Isoleucine & 2.6 & 3.1 & 1.1 & 38.3 & 40.3 & 34.1 \\
\hline Leucine & 4.0 & 4.4 & 1.9 & 58.7 & 56.1 & 60.5 \\
\hline Tyrosine & 2.5 & 3.3 & 1.0 & 25.7 & 29.5 & 21.7 \\
\hline Phenylalanine & 3.1 & 3.9 & 1.1 & 34.5 & 38.1 & 26.3 \\
\hline Tryptophan & 0.9 & 1.6 & 0.4 & 7.3 & 11.2 & 7.1 \\
\hline \multirow[t]{2}{*}{ Total protein } & 60.6 & 69.5 & 28.1 & & & \\
\hline & & $\begin{array}{l}\text { cted } f \\
\text { rmined } \\
\text { rmined }\end{array}$ & $\begin{array}{l}\text { tction. } \\
\text { eic acid } \\
\text { rboxy }\end{array}$ & & & \\
\hline
\end{tabular}

Table 4. Stoicheiometry of the chemical changes resulting from alkaline $\beta$-elimination

\begin{tabular}{|c|c|c|c|}
\hline Moiety & $\begin{array}{l}\text { Amount in acid } \\
\text { hydrolysed dry } \\
\text { ovomucin complex } \\
\left(\mathrm{mol} / 10^{5} \mathrm{~g}\right)\end{array}$ & $\begin{array}{l}\text { Amount in alkali- } \\
\text { treated acid } \\
\text { hydrolysed dry } \\
\text { ovomucin complex } \\
\left(\mathrm{mol} / 10^{5} \mathrm{~g}\right)\end{array}$ & $\begin{array}{c}\text { Change } \\
\left(\mathrm{mol} / 10^{5} \mathrm{~g}\right)\end{array}$ \\
\hline $\begin{array}{l}\text { Glucosamine } \\
\text { Galactosamine }\end{array}$ & $\begin{array}{l}36.0 \\
18.0\end{array}$ & $\begin{array}{r}38.9 \\
5.9\end{array}$ & $\begin{array}{r}+2.9 \\
-12.1\end{array}$ \\
\hline Threonine* & 45.1 & 33.3 & -11.8 \\
\hline Serine* & 49.5 & 37.2 & -12.3 \\
\hline Cystine (half) & 34.1 & Trace & -34.1 \\
\hline Lysine & 33.5 & 13.1 & -20.4 \\
\hline
\end{tabular}

* Corrected for destruction during hydrolysis.

major amino acids in the $\beta$-ovomucin preparation. As similar amounts of tyrosine and tryptophan were present in the reduced $\alpha$-ovomucin and $\beta$ ovomucin, the determination of protein by measuring $E_{276}$ during the fractionation procedures was justified.

Alkaline $\beta$-elimination. The ovomucin complex dissolved slowly in $0.5 \mathrm{M}$-sodium hydroxide and showed an increased extinction at $245 \mathrm{~nm}$ as compared with solutions of reduced-alkylated ovomucin complex. Further, the u.v. spectrum of the alkalitreated ovomucin showed an inflexion point at $245 \mathrm{~nm}$, thus suggesting the formation of conjugated double bonds. Analysis of the hydrolysates 
of the alkali-treated ovomucin complex showed that appreciable amounts of threonine, serine, lysine, galactosamine and cystine were destroyed by sodium hydroxide (Table 4). An unknown ninhydrin-positive substance was eluted from the $20 \mathrm{~cm}$ column used for the determination of hexosamines in hydrolysates of the alkali-treated ovomucin complex. This substance was eluted from the ion-exchange resin after galactosamine but before lysine.

\section{DISCUSSION}

In our experiments the yields of insoluble ovomucin complex accounted for approx. $0.2 \%$ (w/w) of the total thick egg-white fraction, or alternatively $1.5 \%(\mathrm{w} / \mathrm{w})$ of the total egg-white solids. Yields of $2 \%(w / w)$ or more have been quoted by other workers (Lanni et al. 1949; Donovan et al. 1970) and it does seem probable that our lower yields of $1.5 \%(w / w)$ may have resulted from losses of ovomucin during the extensive purification procedures (Robinson \& Monsey, $1969 a$ ). However, in some cases other workers have used different methods for the preparation of ovomucin that often use precipitation at $\mathrm{pH} 4.5$ (Lanni et al. 1949). It seems likely under the conditions we have used, where the $\mathrm{pH}$ value of eggwhite of newly laid eggs is approx. pH 7.5, that we may have isolated only those ovomucin components that form an ionic complex with lysozyme at low ionic strength (Robinson \& Monsey, 1969a,b). Further, Brooks \& Hale (1961) did show that their method, which we have used, gave a product less heavily contaminated and consequently smaller in amount than the method of Lanni et al. (1949).

Because disc electrophoresis in urea, electrophoresis on cellulose acetate strips, continuous electrophoresis on the Hannig electrophoretic separator and gel filtration showed the absence of other proteins, it is concluded that our preparations of the ovomucin complex are free of other contaminating egg-white proteins. Further, if any bound lysozyme had been present in our preparations this would have been separated from the reduced ovomucin complex during gel filtration on Sephadex G-200 in the presence of either guanidine hydrochloride or urea (Robinson \& Monsey, $1969 a, b)$.

The addition of guanidine hydrochloride to the caesium chloride solutions used for forming the density gradients enabled us first to dissociate the reduced ovomucin complex and secondly to separate appreciable amounts of the reduced $\alpha$-ovomucin and $\beta$-ovomucin. Further application of this technique may afford a simple method for fractionating protein-glycoprotein complexes and mucopolysaccharides that cannot be completely dissociated during ion-exchange chromatography and electrophoresis. However, we consider that it would be unwise to calculate the buoyant densities and apparent molecular weights from the schlieren patterns of the analytical density-gradient experiments until more is known about the distribution of guanidine hydrochloride in caesium chloride density gradients and its possible effect on the density gradient produced during ultracentrifugation.

The failure to account, by chemical analysis, for the total weights of the preparations of reduced $\alpha$-ovomucin and reduced $\beta$-ovomucin is not unprecedented for glycoproteins and may have been due to the application of hydrolysis conditions found to be optimum for analysis of only the ovomucin complex. In view of the finding that reduced $\beta$-ovomucin contained $57.5 \%(\mathrm{w} / \mathrm{w})$ of carbohydrate, whereas reduced $\alpha$-ovomucin contained only $14.7 \%(w / w)$, it seems that such hydrolysis conditions may not have been optimum for analysis of the fractionated ovomucin components. However, at present the absence of other organic substances cannot yet be proved.

The reduced $\beta$-ovomucin fraction is distinguished from all other known egg-white glycoproteins by its high carbohydrate content, which represented approx. $57 \%(w / w)$ of the material. Further, the reduced $\beta$-ovomucin fraction is the only egg-white glycoprotein fraction that contains significant amounts of galactosamine and large amounts of sialic acid (Table 2). As a small but significant amount of ester sulphate was found to be present in the $\beta$-ovomucin fraction, it seems that this fraction may contain sulphated glycoproteins.

Reduced $\alpha$-ovomucin is similar to the other eggwhite glycoproteins in so far as its carbohydrate moiety contains mainly equimolar amounts of $N$ acetylglucosamine and mannose. Future work might show that the relatively small amounts of $N$-acetylgalactosamine, sialic acid and galactose found in reduced $\alpha$-ovomucin are due to the presence of small amounts of the reduced $\beta$-ovomucin in our preparation of $\alpha$-ovomucin. However, by the techniques we have used so far, reduced $\alpha$-ovomucin seems to be homogeneous. As cystine was not detected during amino acid analysis and addition of a relatively large amount of dithiothreitol (3mg) to the reduced $\alpha$-ovomucin (4mg) did not change the sedimentation-velocity pattern of this preparation, the apparent weight-average molecular weight of 210000 seems to be that of the fully reduced monomer unit, unless the reduced $\alpha$-ovomucin monomer units are cross-linked by bonds not susceptible to disulphide-bond-reducing agents or 5 M-guanidine hydrochloride. However, our estimation of molecular weight may only be approximate because experiments were carried out at only one

Bioch. 1971, 121 
concentration of reduced $\alpha$-ovomucin and one centrifuge speed in the presence of only $5 \mathrm{M}$-guanidine hydrochloride. Further, we have not attempted to verify by $\boldsymbol{N}$-terminal analysis whether the reduced $\alpha$-ovomucin contained a single polypeptide chain, although investigations with 2,4dinitrofluorobenzene and large amounts (240 mg) of ovomucin complex did not reveal the presence of any $\boldsymbol{N}$-terminal groups. If our preparation of reduced $\alpha$-ovomucin did contain a single polypeptide chain this would have a molecular weight of 145000. Donovan et al. (1970) reported a viscosity-average molecular weight of 163000 for ovomucin monomer units. However, their preparation, which was obtained after precipitation at pH4.5, as judged from their analysis, may be a mixture of the $\alpha$-ovomucin and $\beta$-ovomucin fractions. Further, their preparations differed from ours in that the major sedimenting component in $6 \mathrm{~m}$-guanidine hydrochloride plus $0.2 \mathrm{M}$-mercaptoethanol had a sedimentation coefficient of $\boldsymbol{s}_{20, w}$ 1.4S. However, as the total sample concentration used by Donovan et al. (1970) and the assumed value for the partial specific volume required for correction of their sedimentation coefficients were not quoted, the corrected sedimentation coefficients given by Donovan et al. (1970) may be only approximate for their reduced-unalkylated preparation.

The almost total release of sialic acid from the ovomucin complex by neuraminidase or by very mild acid hydrolysis suggests a terminal location for sialic acid in the oligosaccharide chains and the absence of $O$-acetyl substituents (Faillard, 1957, 1959). Neuraminidase appears to cleave only sialic acid residues joined to galactose or to $N$-acetylgalactosamine (Gottschalk, 1960), and hence a terminal sialylsialic acid disaccharide is unlikely. Sialic acid has usually been found linked ketosidically to galactose or $N$-acetylgalactosamine, and sialyl - $(2 \rightarrow 6)-N$ - acetylgalactosamine prosthetic groups occur almost exclusively in submaxillarygland mucin (Graham \& Gottschalk, 1960). However, the complete absence of other sialic acids cannot be claimed, as there was a discrepancy of $5 \%$ (w/w) between the direct Ehrlich and thiobarbituric acid assay procedures (Warren, 1959, 1960; Gibbons, 1963). Because $24.1 \mu \mathrm{mol} / 10^{5} \mathrm{~g}$ of hydroxy amino acids were destroyed by the alkaline $\beta$. elimination reaction, it does seem very likely that at least some of the oligosaccharides present in the ovomucin complex were linked to the polypeptide parts through glycosidic linkages with the hydroxyl groups of both threonine and serine. As 67.2\% (w/w) of galactosamine was destroyed during the alkaline treatment, some of the glycosidic bonds to the hydroxy amino acids probably involved $N$ acetylgalactosamine and would be present mainly in the reduced $\beta$-ovomucin fraction. However, as the ovomucin complex $\left(10^{5} \mathrm{~g}\right)$ contained only $18 \mu$ mol of $N$-acetylgalactosamine, and $24.1 \mu \mathrm{mol}$ of hydroxy amino acids was destroyed during alkaline treatment, it is thought that other linkages to the hydroxyl groups of either serine or threonine that are susceptible to alkali may be present in the ovomucin complex.

Glucosamine, which was not destroyed during the alkali treatment, may be linked to a polypeptide through the more alkali-stable glycosylamine bond (Neuberger, 1964). Loss of half of the total lysine during the alkaline $\beta$-elimination reaction was surprising, but a similar loss of lysine during alkali treatment of proteins rich in cystine has been reported. Bohak (1964) showed that some lysyl residues were converted into lysinoalanine during alkaline treatment of ribonuclease, lysozyme, papain, chymotrypsin, bovine plasma albumin and phosvitin, and suggested that lysinoalanine was formed by the addition of the $\epsilon$-amino group of lysine to the double bond of a dehydroalanyl residue formed during a $\beta$-elimination reaction on cystine residues. As shown in Table 4 cystine was also destroyed during the $\beta$-elimination reaction with the ovomucin complex. Further, the elution position of the unidentified ninhydrin-positive substance present in acid hydrolysates of only alkalitreated ovomucin complex corresponded to that reported by Bohak (1964) for lysinoalanine. However, we have not yet attempted to identify the proposed lysinoalanine.

These studies indicate that the purified dry ovomucin complex isolated from thick egg-white may be a co-polymer of infinite size composed of basically two types of glycoproteins, some of which may be sulphated. Because ovomucin has for a long time been thought to play an important part in determining the gel-like properties of thick eggwhite, the presence in our ovomucin preparations of $\beta$-ovomucin, which contained approx. $57 \%$ (w/w) of carbohydrate, of which $14 \%(w / w)$ was sialic acid, may be of special significance, even though the $\beta$-ovomucin fraction may only represent $0.1 \%$ $(w / w)$ of the thick liquid egg-white. Indeed, it is known that small amounts of polysaccharides can cause gel formation (Rees, 1969). The ease with which both isolated reduced $\alpha$-ovomucin and $\beta$-ovomucin derivatives self-associate suggests that a similar association may occur between the natural $\alpha$-ovomucin and $\beta$-ovomucin fractions present in thick egg-white and thus account for the gelatinous and viscous properties of the thick egg-white fraction. Further, it is possible that increased strength might be imparted to the thick egg-white gel by disulphide bonding between the various $\alpha$-ovomucin and $\beta$-ovomucin co-polymers. 


\section{REFERENCES}

Bezkorovainy, A. (1963). Archs Biochem. Biophys. 101, 66.

Bitter, T. \& Ewins, R. (1961). Biochem. J. 81, 43 P.

Blix, G. \& Lindberg, E. (1960). Acta chem. scand. 14, 1809.

Bohak, Z. (1964). J. biol. Chem. 239, 2878.

Brooks, J. \& Hale, H. P. (1959). Biochim. biophys. Acta, 32, 237.

Brooks, J. \& Hale, H. P. (1961). Biochim. biophys. Acta, 46, 289.

Clamp, J. R., Dawson, G. \& Hough, L. (1967). Biochim. biophys. Acta, 148, 342.

Creeth, J. M. \& Denborough, M. A. (1970). Biochem. J. $117,879$.

Davis, J. G., Zahnley, J. C. \& Donovan, J. W. (1969). Biochemistry, Easton, 8, 2044.

Dische, Z. (1955). In Methods in Biochemical Analysis, vol. 2, p. 313. Ed. by Glick, D. New York : Interscience Publishers Inc.

Dische, Z. \& Shettles, L. B. (1948). J. biol. Chem. 175, 595.

Donovan, J. W., Davis, J. G. \& White, L. M. (1970). Biochim. biophys. Acta, 207, 190.

Eichholz, A. (1898). J. Physiol., Lond., 23, 163.

Faillard, H. (1957). Hoppe-Seyler's Z. physiol. Chem. 307, 62.

Faillard, H. (1959). Hoppe-Seyler's Z. physiol. Chem. 317, 257.

Gibbons, M. N. (1963). Analyst, Lond., 80, 268.

Gottschalk, A. (1960). Chemistry and Biology of Sialic Acids, p. 65. New York: Cambridge University Press.

Graham, E. R. B. \& Gottschalk, A. (1960). Biochim. biophys. Acta, 38, 513.

Hannig, K. (1964). Hoppe-Seyler's Z. physiol. Chem. 338, 211.

Jones, A. S. \& Lethan, D. S. (1956). Analyst, Lond., 81, 15.

Katz, S. (1968). Biochim. biophys. Acta, 154, 468.

Kawahara, K. \& Tanford, C. (1966). J. biol. Chem. 241, 3228.

Ketterer, B. (1965). Biochem. J. 96, 372.

Klenk, E. \& Uhlenbruck, G. (1957). Hoppe-Seyler's Z. physiol. Chem. 307, 266.

Lanni, F., Sharp, D., Eckert, E. A., Dillon, E. S., Beard, D. \& Beard, J. W. (1949). J. biol. Chem. 179, 1275.

Markham, R. (1960). Biochem. J. 77, 516.
Melamed, M. D. \& Green, N. M. (1963). Biochem. J. 89, 591.

Neuberger, A. (1964). Abstr. 6th int. Cong. Biochem., New York, vol. 2, p. 105.

Odin, L. (1951). Acta chem. scand. 5, 1420.

Ogston, A. G. (1964). Analyt. Biochem. 8, 337.

Parkinson, T. L. (1966). J. Sci. Fd Agric. 17, 101.

Partridge, S. M. (1949). Nature, Lond., 164, 443.

Partridge, S. M. \& Elsden, D. F. (1961). Biochem. J. 80, 34 P.

Rees, D. A. (1969). Adv. Carbohyd. Chem. 24, 267.

Reissig, J. L., Strominger, J. L. \& Leloir, L. F. (1955). J. biol. Chem. 217, 959.

Robinson, D. S. \& Monsey, J. B. (1964). Biochim. biophys. Acta, 83, 368.

Robinson, D. S. \& Monsey, J. B. (1966). Biochem. J. $100,61 P$.

Robinson, D. S. \& Monsey, J. B. (1969a). Biochem. J. 115, 64 P.

Robinson, D. S. \& Monsey, J. B. (1969b). Biochem. J. 115,65 P.

Roth, H., Segal, S. \& Bertoli, D. (1965). Analyt. Biochem. $10,32$.

Salton, M. R. J. (1960). Nature, Lond., 186, 966.

Small, P. A. \& Lamm, M. E. (1966). Biochemistry, Easton, 5, 259.

Spies, J. R. \& Chambers, D. C. (1949). Ind. Engng Chem., analyt. Edn, 20, 30.

Stoffyn, P. J. \& Jeanloz, R. W. (1954). Archs Biochem. Biophys. 52, 373.

Svennerholm, L. (1957). Biochim. biophys. Acta, 24, 604.

Svennerholm, E. \& Svennerholm, L. (1958). Nature, Lond., 181, 1154.

Tanford, C., Kawahara, K. \& Lapanje, S. (1967). J. Am. chem. Soc. 89, 729.

Warren, L. (1959). J. biol. Chem. 234, 1971.

Warren, L. (1960). Nature, Lond., 186, 237.

Whitehouse, M. W. \& Zilliken, F. (1960). In Methods in Biochemical Analysis, vol. 8, p. 199. Ed. by Glick, D. New York: Interscience Publishers Inc.

Williams, J. (1968). Biochem. J. 108, 57.

Yemm, E. W. \& Willis, A. J. (1954). Biochem. J. 57, 508.

Young, E. G. (1937). J. biol. Chem. 120, 1.

Yphantis, D. A. (1964). Biochemistry, Easton, 3, 297. 